\title{
Review
}

\section{The Metabolic Syndrome as a Concept of Adipose Tissue Disease}

\author{
Eiji ODA ${ }^{1)}$
}

\begin{abstract}
The metabolic syndrome is a constellation of interrelated metabolic risk factors that appear to directly promote the development of diabetes and cardiovascular disease. However, in 2005, the American Diabetes Association and the European Association for the Study of Diabetes jointly stated that no existing definition of the metabolic syndrome meets the criteria of a syndrome, and there have been endless debates on the pros and cons of using the concept of this syndrome. The controversy may stem from confusion between the syndrome and obesity. Obesity is an epidemic, essentially contagious disease caused by an environment of excess nutritional energy and reinforced by deeply rooted social norms. The epidemic of obesity should be prevented or controlled by social and political means, similar to the approaches now being taken to combat global warming. The diagnosis of metabolic syndrome is useless for this public purpose. The purpose of establishing criteria for diagnosing metabolic syndrome is to find individuals who are at increased risk of diabetes and cardiovascular disease and who require specific therapy including diet and exercise. The syndrome may be an adipose tissue disease different from obesity; in that case, it would be characterized by inflammation clinically detected through systemic inflammatory markers such as high-sensitivity Creactive protein and insulin resistance reflecting histological changes in adipose tissue. However, many problems in defining the optimal diagnostic criteria remain unresolved. (Hypertens Res 2008; 31: 1283-1291)
\end{abstract}

Key Words: metabolic syndrome, obesity, diabetes, cardiovascular disease, inflammation

\section{Introduction}

For the past several decades, cardiovascular disease and diabetes have been major causes of morbidity and mortality in the Western developed world, where obesity prevails. Considerable effort has been spent on understanding the underlying biology of cardiovascular disease and on identifying its risk factors. As these factors have been identified, it has become apparent that they tend to cluster within individuals. The metabolic syndrome is a constellation of interrelated metabolic risk factors that appear to directly promote the development of diabetes and cardiovascular disease. The predominant underlying mechanisms for the syndrome appear to be insulin resistance $(1,2)$, abdominal obesity $(3,4)$, and inflammation $(5,6)$. Other associated conditions may be diet (7-9), smoking (10), physical inactivity (11), aging (12), socioeconomic status (9), hormonal imbalance (13), and xenobiotics (14).

\section{Clinical Aspects of the Metabolic Syndrome}

In 1981, Ruderman et al. pointed out that there were metabolically obese, normal-weight (MONW) individuals who might be characterized by hyperinsulinemia and possibly increased fat cell size (15). In 1988, Reaven proposed the label syndrome $\mathrm{X}$ to describe the phenomenon in which individuals displaying a cluster of insulin resistance and compensatory hyperinsulinemia, high plasma triglyceride and low high-density lipoprotein (HDL) cholesterol concentrations, and hypertension were at significantly increased risk of cardiovascular disease (1). The following year, Kaplan added abdominal obesity to this syndrome, subtracted hypo-HDL-cholesterol-

From the ${ }^{1)}$ Medical Check-up Center, Tachikawa Medical Center, Nagaoka, Japan.

Address for Reprints: Eiji Oda, M.D., Medical Check-up Center, Tachikawa Medical Center, Nagamachi 2-2-16, Nagaoka 940-0053 Japan. E-mail: ijie@venus.sannet.ne.jp

Received December 20, 2007; Accepted in revised form March 24, 2008. 
emia, and renamed it the "deadly quartet" (3). In 1991, DeFronzo and Ferrannini renamed syndrome $\mathrm{X}$ the insulin resistance syndrome (IRS) (2). In 1994, Nakamura et al. proposed the name "visceral fat syndrome," considering subcutaneous fat as a rather protective factor against the morbid effects of visceral fat (16), and in 1998, Lamarche et al. reported a combination of hyperinsulinemia, elevated apolipoprotein B, and small dense low-density lipoprotein (LDL) cholesterol as the "atherogenic metabolic triad" (17). In 1999, the World Health Organization (WHO) defined the criteria of IRS and introduced the name metabolic syndrome (18). The European Group for the Study of Insulin Resistance (EGIR) proposed a modified version of the metabolic syndrome to be used for nondiabetic subjects only and renamed it IRS (19). In 2000, Lemieux et al. proposed the "hypertriglyceridemic waist" as a marker of the atherogenic metabolic triad in men (4). In 2001, the Expert Panel on the Detection, Evaluation, and Treatment of High Blood Cholesterol in Adults (ATP III) reported adoption of the user-friendly definition of the metabolic syndrome put forth by the Third Report of the National Cholesterol Education Program (NCEP) (20), and this definition and its modified versions were used worldwide. The NCEP definition did not require demonstration of insulin resistance per se. It was noted that exact measures of insulin resistance were laborious and not well standardized, and that surrogate measures, such as glucose tolerance tests, were not routinely used in clinical practice. Although the ATP III recognized the clustering phenomenon of metabolic risk factors, it was not convinced that insulin resistance was the only mechanistic pathogenesis. Thus, the NCEP definition required no single factor for diagnosis, instead requiring the presence of 3 out of 5 risk factors as a diagnostic requirement; these were abdominal obesity defined as waist circumference (WC) $\geq 102 \mathrm{~cm}$ in men and $\geq 88 \mathrm{~cm}$ in women, elevated triglycerides defined as $\geq 150 \mathrm{mg} / \mathrm{dL}$, reduced HDL cholesterol defined as $<40 \mathrm{mg} / \mathrm{dL}$ in men and $<50 \mathrm{mg} / \mathrm{dL}$ in women, elevated blood pressure defined as systolic pressure $\geq 130$ $\mathrm{mmHg}$ and/or diastolic pressure $\geq 85 \mathrm{mmHg}$, and elevated fasting glucose defined as $\geq 110 \mathrm{mg} / \mathrm{dL}$. In 2003, the American Association of Clinical Endocrinologists (AACE) modified this definition to refocus on insulin resistance as the primary cause of the metabolic syndrome and again returned to the name IRS (21). The major criteria in the AACE definition were impaired glucose tolerance, elevated triglycerides, reduced HDL cholesterol, elevated blood pressure, and obesity. No specified number of factors was required for diagnosis, which was left to clinical judgment. Once a person develops diabetes, the term IRS no longer applies. In 2004, Ridker et al. proposed the inclusion of high-sensitivity Creactive protein (hs-CRP) as a component of the metabolic syndrome because hs-CRP is strongly related to obesity and insulin resistance, and was established as a risk factor of cardiovascular disease (5).

In 2005, the International Diabetes Federation (IDF) issued a new definition of the metabolic syndrome, in which the presence of abdominal obesity is necessary and the presence of 2 additional factors originally listed in the NCEP definition is sufficient for diagnosis (22). But, impaired fasting glucose was modified as $\geq 100 \mathrm{mg} / \mathrm{dL}$ and the criteria for abdominal obesity were specified by race: that is, for people of European origin, the cut points of WC were $94 \mathrm{~cm}$ in men and $80 \mathrm{~cm}$ in women; for Asian populations, the WC points were $90 \mathrm{~cm}$ in men and $80 \mathrm{~cm}$ in women. In the same year, the American Heart Association (AHA) and the National Heart, Lung, and Blood Institute (NHLBI) jointly criticized the IDF definition of the metabolic syndrome and slightly revised the NCEP definition. Consequently, the cut point of impaired fasting glucose became $100 \mathrm{mg} / \mathrm{dL}$ and the criteria of abdominal obesity became race-specific (23). Also in 2005, the American Diabetes Association (ADA) and the European Association for the Study of Diabetes (EASD) jointly stated that no existing definition of the metabolic syndrome meets the criteria of a syndrome and that one should not apply the "metabolic syndrome" to individuals (24). The joint statement named eight concerns regarding the metabolic syndrome, summarized as follows.

1) The criteria are ambiguous or incomplete. The rationale for the thresholds are ill defined. 2) The value of including diabetes in the definition is questionable. 3) Insulin resistance as the unifying etiology is uncertain. 4) There is no clear basis for including or excluding other risk factors of cardiovascular disease. 5) The risk value of cardiovascular disease is variable and dependent on the specific risk factors present. 6) The risk of cardiovascular disease associated with the "syndrome" appears to be no greater than the accumulated risk of the sum of the syndrome's parts. 7) Treatment for the syndrome is no different than the treatment for its components. 8) The medical value of diagnosing the syndrome is unclear.

After the publication of this statement and continuing to the present, there have been endless debates regarding the pros and cons of the concept of the metabolic syndrome (25-32). In these debates, Reaven endorsed the ADA/EASD joint statement and noted that it is possible to create an almost infinite number of scenarios in which persons who do not meet the diagnostic criteria for the metabolic syndrome would be at greater risk of cardiovascular disease than those who do (27). Grundy asserted that the metabolic syndrome is not meant to be a risk-assessment tool for short-term $(<10$-year) risk, but rather is meant to identify people at higher long-term risk for cardiovascular disease and diabetes, since the metabolic syndrome is a progressive disorder (25). However, Sundstrom et al. reported that the metabolic syndrome did not provide risk information above and beyond that of its individual components in their community-based long-term cohort study with 30 years of follow-up (33). Amid these debates, the AHA and ADA jointly issued a scientific statement titled "Preventing cardiovascular disease and diabetes. A call to action from the American Diabetes Association and the American Heart Association," in which they stated that despite the many unresolved scientific issues concerning the metabolic syndrome, a 
Table 1. The Two Pedigrees of Concepts for Metabolic Syndrome

\begin{tabular}{|c|c|c|c|}
\hline \multirow{9}{*}{$\begin{array}{l}\text { A: Concepts which consider } \\
\text { obesity as the essential feature } \\
\text { of metabolic syndrome }\end{array}$} & 1951 & Jouve et al. & Android obesity as a risk factor of cardiovascular disease \\
\hline & 1982 & Kissebah et al. & Upper-body obesity \\
\hline & 1985 & Bjorntorp & Abdominal obesity \\
\hline & 1987 & Matsuzawa et al. & $\begin{array}{l}\text { Visceral fat obesity (regarding subcutaneous fat as a protec- } \\
\text { tive factor from the morbid effect of visceral fat) }\end{array}$ \\
\hline & 1989 & Kaplan & Deadly quartet \\
\hline & 1994 & Nakamura et al. & Visceral fat syndrome based on visceral fat obesity \\
\hline & 2000 & Lemieux & Hypertriglyceridemic waist \\
\hline & 2005 & IDF & $\begin{array}{l}\text { Abdominal obesity as the essential component of metabolic } \\
\text { syndrome }\end{array}$ \\
\hline & 2005 & \multicolumn{2}{|c|}{ Japanese definition of metabolic syndrome based on visceral fat syndrome } \\
\hline \multirow{10}{*}{$\begin{array}{l}\text { B: Concepts which regard } \\
\text { obesity as a non-essential fea- } \\
\text { ture of metabolic syndrome }\end{array}$} & 1981 & Rudermann et al. & MONW individuals with hyperinsulinemia \\
\hline & 1988 & Reaven & Syndrome $\mathrm{X}$ with insulin resistance \\
\hline & 1991 & DeFronzo and Ferrannini & Insulin resistance syndrome \\
\hline & 1993 & Hotamisligil et al. & $\begin{array}{l}\text { Inflammation }(\mathrm{TNF}-\alpha) \text { as a linker between obesity and insu- } \\
\text { lin resistance }\end{array}$ \\
\hline & 1999 & WHO & The first definition of metabolic syndrome \\
\hline & 1999 & EGIR & Insulin resistance syndrome excluding diabetes \\
\hline & 2001 & NCEP & Metabolic syndrome defined by 3 out of 5 components \\
\hline & 2003 & AACE & $\begin{array}{l}\text { Subjective criteria of insulin resistance syndrome excluding } \\
\text { diabetes }\end{array}$ \\
\hline & 2004 & Ridker & hs-CRP as a component of metabolic syndrome \\
\hline & 2006 & Oda & $\begin{array}{l}\text { Replacing waist circumference by hs-CRP among } 5 \text { compo- } \\
\text { nents of metabolic syndrome }\end{array}$ \\
\hline
\end{tabular}

IDF, International Diabetes Federation; MONW, metabolically-obese, normal-weight; TNF- $\alpha$, tumor necrosis factor- $\alpha$; WHO, World Health Organization; EGIR, European Group for the Study of Insulin Resistance; NCEP, National Cholesterol Education Program; AACE, American Association of Clinical Endocrinologists; hs-CRP, high-sensitivity C-reactive protein.

number of cardiometabolic risk factors, such as hyperglycemia, overweight/obesity, elevated blood pressure, and dyslipidemia, are clearly related to diabetes and cardiovascular disease. The report recommended lifestyle modification with attention to weight loss and physical activity regardless of a diagnosis of metabolic syndrome because obesity, a prevailing threat in the Western world, is often a visible marker of other underlying risk factors (34). Since 2004, many epidemiological studies and meta-analyses of the metabolic syndrome have been reported (35-41), most of which have shown that the presence of the metabolic syndrome indicated a relative risk of a cardiovascular incident and mortality of around 1.5 to 2.5. After the issue of IDF definition, most of the studies comparing different definitions of the metabolic syndrome have suggested that the IDF definition was not superior to the NCEP definition, and pointed out that the former failed to identify metabolically abnormal but non-obese individuals known to be predisposed to diabetes and cardiovascular disease (42-48).

In 2007, the Association for Weight Management and Obesity Prevention, the Obesity Society, the American Society for Nutrition, and the ADA issued a consensus statement concerning WC (49). Their opinion held that no standard method provides the best correlation with disease risk for measuring
WC, and that different anatomical landmarks have been used to measure WC in different studies. The current WC cut points were derived by regression from body mass index (BMI), and there is not yet a compelling body of evidence demonstrating that $\mathrm{WC}$ provides clinically meaningful information that is independent of well-known cardiometabolic risk factors. Therefore, the clinical usefulness of measuring WC is limited and unlikely to affect clinical management when BMI and other obesity-related risk factors are already being determined. Further studies are needed to establish the most appropriate WC cut points; this effort will be complex because the cut points are likely influenced by sex, race/ethnicity, age, BMI, and other factors. Previously, I proposed replacing WC with hs-CRP among the 5 components of metabolic syndrome because hs-CRP is the most widely used marker of low-grade inflammation, is strongly related to obesity and insulin resistance, and is an established risk factor for diabetes and cardiovascular disease (50). Of course, this proposal should be tested by longitudinal studies.

In summary, there have been two evolving lines of thought regarding the metabolic syndrome, as shown in Table 1. One considers the macroscopic anatomy of adipose tissue-that is, fat mass and distribution - as the essential feature of the syndrome (Table 1A). The other stands on the endocrine, inflam- 
Table 2. Multi-Faceted View Points of Obesity and Adipose Tissue Disease

\begin{tabular}{ll}
\hline \multicolumn{1}{c}{ View points } & \multicolumn{1}{c}{ Markers } \\
\hline General obesity & BMI, total fat mass, etc. \\
Abdominal obesity & waist circumference, waist-to-hip ratio, etc. \\
Visceral obesity & visceral fat area, visceral fat volume, etc. \\
Ectopic fat deposits & fatty liver, intra-muscular lipid, etc. \\
Endocrine disorders & leptin, adiponectin, RBP4, aFABP, etc. \\
Low-grade inflammation & hs-CRP, MCP-1, PAI-1, TNF- $\alpha$, etc. \\
Histological changes & crown-like structure (enlarged adipocytes, adipocyte death, and accumulation of macrophages) \\
\hline
\end{tabular}

BMI, body mass index; RBP4, retinol binding protein 4; aFABP, adipocyte-type fatty acid binding protein; hs-CRP, high-sensitivity Creactive protein; MCP1, monocyte chemoattractant protein-1; PAI-1, prasminogen activator inhibiter-1; TNF- $\alpha$, tumor necrosis factor- $\alpha$.

matory, and metabolic features of adipose tissue (Table 1B).

\section{Obesity vs. Adipose Tissue Disease}

\section{Obesity as a Concept of Excess Body Fat Mass}

Many methods have been developed to measure body fat mass and to define obesity as a state of excess body fat mass. However, no method or definition is clinically superior to BMI at present. A BMI cut point of 30 is generally used to define obesity, and that of $25 \mathrm{~kg} / \mathrm{m}^{2}$ is used to discriminate pre-obese or overweight persons from normal-weight persons. The prevalence of obesity was reported to be $32.2 \%$ in 2003-2004 in the United States (51) and 2.9\% in 2004 in Japan (52). In a large prospective cohort study in the United States, the risk of death was 20 to $40 \%$ higher in overweight persons and two to at least three times higher in obese persons among those who had never smoked, compared to normalweight, nonsmoking individuals (53). In Japan, compared with persons with BMI $23.0-24.9 \mathrm{~kg} / \mathrm{m}^{2}$, obese persons had a higher risk of coronary heart disease (relative risk: 1.8 with a 95\% confidence interval: 1.1-3.0) in men not in women, but no significant increase in risk was detected for overweight persons (54).

\section{Types of Obesity According to the Topology of Fat Deposition}

In 1982, Kissebah et al. reported that body fat distribution and fat cell size were important markers of metabolic complications of obesity in women (55). Despres et al. later emphasized the role of visceral fat in the association between regional adipose tissue distribution and glucose tolerance in premenopausal obese women (56). Later, WC was proposed as a marker of abdominal (central, upper body, apple type, or android) or visceral obesity and obesity-related metabolic disorders (57). However, there is a report that WC is not superior to BMI as a predictive marker of diabetes (58), and the Association for Weight Management and Obesity Prevention, the Obesity Society, the American Society for Nutrition, and the ADA jointly criticized the clinical usefulness of WC (49). In
1997, a review by Matsuzawa found that insulin resistance was much more severe in visceral fat obesity than in subcutaneous fat obesity, based on limited data, and he proposed that subcutaneous fat might have some protective role against the morbid effect of visceral fat (59). However, in 2006, Reaven showed that among 19 qualified studies, there were only 2 where the relation between insulin-mediated glucose uptake (IMGU) and visceral fat was quite different from that between IMGU and abdominal subcutaneous fat, whereas in the other 17 studies the correlation coefficients between IMGU and visceral fat or subcutaneous fat did not vary a great deal (27). In 8 of those studies, they were somewhat higher with visceral fat; in 7 , they were higher with subcutaneous fat; and in the remaining 2, they were identical. In 2007, Fox et al. examined the association of abdominal subcutaneous adipose tissue (SAT) volume and visceral adipose tissue (VAT) volume, assessed by multi-detector CT, with metabolic risk factors in the Framingham Heart Study and reported that, although VAT was more highly correlated with metabolic risk factors, it was possible that SAT volume actually contributes to a more absolute risk because SAT volume was greater than VAT volume (60). Later, Pou et al. examined the relations of SAT volume and VAT volume to circulating inflammatory and oxidative stress biomarkers in 1,250 Framingham Heart Study participants; they concluded that SAT and VAT were similarly associated with elevated concentrations of multiple inflammatory biomarkers (61). These results clearly show that SAT has no protective role against the morbid effect of VAT. Kelley and Goodpaster analyzed the linkage between excess fat storage within skeletal muscle and insulin resistance, and showed the effect of weight loss on skeletal muscle substrate metabolism (62). Montani et al. discussed the role of ectopic fat storage in the heart, blood vessels, and kidneys in the pathogenesis of cardiovascular disease (63), and Rasouli et al. also emphasized the role of ectopic lipid accumulation in the pathogenesis of the metabolic syndrome (64). Kotronen and Yki-Jarvinen showed that liver fat storage is highly significantly and linearly correlated with all components of the metabolic syndrome independent of obesity, and proposed fatty liver as a novel component of the syndrome (65). 
Table 3. Up-to-Date Concept of Metabolic Syndrome

\begin{tabular}{c}
\hline Chronic continued excess-energy environment surrounding cells \\
$\downarrow$ \\
Stress upon endoplasmic reticulum, nucleus, and mitochondria \\
$\downarrow$ \\
Enlargement and death of adipocytes with \\
accumulation of macrophages \\
(crown-like structure) \\
$\downarrow$ \\
Inflammation and insulin resistance \\
$\downarrow$ \\
Clustering of metabolic risk factors \\
$\downarrow$ \\
Diabetes and cardiovascular disease
\end{tabular}

\section{Adipose Tissue Disease as a Metabolic Syn- drome Concept}

Adipose tissue secretes many hormone-like substances, such as tumor necrosis factor- $\alpha$ (TNF- $\alpha)(66)$, leptin (67), adiponectin (68), resistin (69), visfatin (70), monocyte chemoattractant protein-1 (MCP-1) (71), retinol binding protein 4 (72), and adipocyte-type fatty acid binding protein (73); and obesity has been considered an endocrine and inflammatory disorder intimately related with insulin resistance rather than merely an anthropometric fatness, a topologically altered fat distribution, or an ectopic fat deposition. Multi-faceted viewpoints and markers of obesity and adipose tissue disease are summarized in Table 2. Hotamisligil et al. reported the adipose expression of TNF- $\alpha$ and a direct role of this inflammatory cytokine in obesity-linked insulin resistance (66). Dandona et al. reported that insulin inhibits nuclear factor- $\kappa \mathrm{B}$ and inhibits inflammation (74). Later, Hotamisligil reviewed the link between cell stress, inflammation, and metabolic disease, focusing on the c-Jun $\mathrm{NH}_{2}$-terminal kinase, on an inhibitor of nuclear factor- $\mathrm{KB}$ kinase, and on obesity-induced endoplasmic reticulum (ER) stress (75). Semenkovich also reviewed insulin resistance and atherosclerosis, emphasizing mitochondrial, nuclear, and ER stress caused by the excess delivery of fuel, and recommended eating less and exercising more (76). A proposed up-to-date concept of metabolic syndrome is summarized in Table 3. Kim et al. reported a transgenic model of extreme obesity associated with an improved metabolic profile compared with the original obese mouse (77). In this transgenic model, adiponectin acts as a peripheral starvation signal promoting the storage of triglycerides preferentially in adipose tissue and reduces the macrophage infiltration into adipose tissue, thus preventing systemic inflammation and insulin resistance. Bains et al. reported a transgenic model of severe visceral obesity without insulin resistance, in which the adipocyte size is not increased and the plasma level of adiponectin is increased (78). Cinti et al. described the necrotic-like death of enlarged adipocytes hav- ing a crown-like structure consisting of activated macrophages, not only in the adipose tissue of obese mice and in both visceral and subcutaneous adipose tissue of obese humans, but also in the adipose tissue of hormone-sensitive lipase-deficient mice, which is a model of adipocyte hypertrophy without obesity but with insulin resistance (79). Kanda et al. reported a transgenic model of mice with normal body and adipose tissue weight, normal adipocyte size, and normal plasma adiponectin level, that manifests macrophage infiltration into adipose tissue, insulin resistance, and glucose intolerance (80). Kamei et al. reported a similar transgenic model and similar results emphasizing the role of circulating MCP-1 (81). Wellen et al. reported a transgenic model of mice that exhibit macrophage infiltration and overt inflammation only in visceral adipose tissue and not in subcutaneous adipose tissue, and that develop spontaneous metabolic disease, manifesting insulin resistance, glucose intolerance, mild hyperglycemia, dyslipidemia, and fatty liver (82). However, in this model of metabolic or visceral fat "syndrome," visceral fat weight was not increased but subcutaneous fat weight and liver weight were increased compared with wild-type mice. Strissel et al. reported adipocyte death and adipose tissue remodeling in mice in which obesity was induced by a highfat diet (83). In this model, adipocyte death and macrophage infiltration in epididymal (visceral) adipose tissue were critical, but the weight of epididymal adipose tissue at a certain stage (12 weeks) of obesity was decreased and liver weight was increased at the same stage. These transgenic and dietinduced obesity animal models indicate that the infiltration of macrophages into adipose tissue and inflammation, rather than increased adipocyte size, adipose tissue mass, or visceral fat mass per se, are crucial for the metabolic consequences of obesity.

In humans, Kolak et al. demonstrated increased macrophage infiltration into subcutaneous adipose tissue and crownlike structures surrounding dead adipocytes in subcutaneous adipose tissue in a high liver fat group compared with a low liver fat group, independent of obesity and fat cell size (84). Although there are few histological studies involving humans $(79,84)$, studies on a marker of systemic inflammation, hs$\mathrm{CRP}$, as a risk factor for diabetes and cardiovascular disease are abundant (85-93), and Ridker et al. proposed hs-CRP as a component of metabolic syndrome because hs-CRP is strongly related to obesity and insulin resistance, and was established as a risk factor for diabetes and cardiovascular disease (5). Though only about one-third of the most insulinresistant individuals are actually obese according to Reaven (27), hs-CRP is significantly positively correlated with plasma leptin levels (94) and significantly negatively related with plasma adiponectin levels (95) even in persons with normal BMI. Nakamura et al. reported that WC has the strongest correlation with hs-CRP among the 5 components of the metabolic syndrome (96). Komatsu et al. reported that adiponectin was significantly correlated with hs-CRP but not with $\mathrm{WC}$ or BMI in a multivariate study among apparently 
healthy Japanese men (97), and Yoneda et al. reported that hs-CRP differentiated nonalcoholic steatohepatitis (NASH) from simple steatosis of the liver, but BMI or visceral fat area did not (98). I and co-workers proposed hs-CRP $\geq 0.65 \mathrm{mg} / \mathrm{L}$ as a component of metabolic syndrome in Japanese (99), and this cut point may also be appropriate not only as a component of metabolic syndrome (100) but also as a risk factor for cardiovascular disease (101), coronary spasm (102), and NASH (98). I proposed replacing WC with hs-CRP as a marker of adipose tissue disease among the 5 NCEP components of the metabolic syndrome, not for diagnosing individuals with metabolic syndrome at present but rather for studying the syndrome; in that report, I also recommended the use of WC, BMI, or other anthropometric markers of obesity as convenient tools for the screening of more proximal risk factors for diabetes and cardiovascular disease (50). However, whether or not this new definition is useful for predicting the risk of diabetes and cardiovascular disease should be evaluated by longitudinal epidemiological studies and histological studies on human visceral adipose tissue in relation to systemic inflammatory markers, including hs-CRP, anthropometric parameters, and visceral fat volume, may clarify the concept of adipose tissue disease.

\section{Conclusions}

Not all obese persons eventually develop diabetes or suffer from cardiovascular disease, and conversely a substantial number of non-obese individuals do suffer from these diseases. Adipose tissue disease, which results from cell stress due to an environment of incessant excess energy and defined by histological features and systemic inflammatory, endocrine, and metabolic parameters, may be different from obesity defined by anthropometric parameters. On the other hand, hs-CRP may be a clinically useful marker of adipose tissue disease. However, obesity is an epidemic disease and a major cause of diabetes and cardiovascular disease in Western developed countries; through social norms, it spreads like an contagious disease (103). Even though the prevalence of obesity is low in Japan, the prevention of obesity is mandated by the national government. It is already proved, in obesity-prevailing countries such as the United States, that threatening people with the term "metabolic syndrome" is useless for the prevention of obesity. The most important preventive strategy in Japan may be stopping the spread of certain aspects of the Western lifestyle, especially of the still-prevalent fast-food diet in American society, by political and economical regulations. Obesity, like global warming, is an "inconvenient truth" in some Western countries, and the therapy for it may be inconvenient political and economic regulations on food culture and lifestyle.

\section{References}

1. Reaven GM: Role of insulin resistance in human disease.
Diabetes 1988; 37: 1595-1607.

2. DeFronzo RA, Ferrannini E: Insulin resistance. A multifaceted syndrome responsible for NIDDM, obesity, hypertension, dyslipidemia, and atherosclerotic cardiovascular disease. Diabetes Care 1991; 14: 173-194.

3. Kaplan NM: The deadly quartet: upper body obesity, glucose intolerance, hypertriglyceridemia and hypertension. Arch Intern Med 1989; 149: 1514-1520.

4. Lemieux I, Pascot A, Couillard C, et al: Hypertriglyceridemic waist: a marker of the atherogenic metabolic triad (hyperinsulinemia; hyperapolipoprotein B; small, dense LDL) in men? Circulation 2000; 102: 179-184.

5. Ridker PM, Wilson PW, Grundy SM: Should C-reactive protein be added to metabolic syndrome and to assessment of global cardiovascular risk? Circulation 2004; 109: 2818 2825.

6. Dandona P, Aljada A, Chaudhuri A, Mohanty P, Garg R: Metabolic syndrome: a comprehensive perspective based on interactions between obesity, diabetes, and inflammation. Circulation 2005; 111: 1448-1454.

7. Iso $\mathrm{H}$, Kobayashi M, Ishihara J, et al: Intake of fish and n-3 fatty acids and risk of coronary heart disease among Japanese: the Japan Public Health Center-based (JPHC) Study Cohort 1. Circulation 2006; 113: 195-202.

8. Ouellet V, Marois J, Weisnagel SJ, Jacques H: Dietary cod protein improves insulin sensitivity in insulin-resistant men and women. Diabetes Care 2007; 30: 2816-2821.

9. Riserus U, Arnlov J, Berglund L: Long-term predictors of insuli resistance. Role of lifestyle and metabolic factors in middle-aged men. Diabetes Care 2007; 30: 2928-2933.

10. Oh SW, Yoon YS, Lee ES, et al: Association between cigarette smoking and metabolic syndrome: the Korea National Health and Nutrition Examination Survey. Diabetes Care 2005; 28: 2064-2066.

11. Gustat J, Srinivasan SR, Elkasabany A, Berenson GS: Relation of self-rated measures of physical activity to multiple risk factors of insulin resistance syndrome in young adults: the Bogalusa Heart Study. J Clin Epidemiol 2002; 55: 9971006.

12. Ford ES, Giles WH, Dietz WH: Prevalence of the metabolic syndrome among US adults: findings from the Third National Health and Nutrition Examination Survey. JAMA 2002; 287: 356-359.

13. Apridonidze T, Essah PA, Iuorno MJ, Nestler JE: Prevalence and characteristics of the metabolic syndrome in women with polycystic ovary syndrome. J Clin Endocrinol Metab 2004; 90: 1929-1935.

14. Lee D, Lee I, Jin S, Steffes M, Jacobs DR Jr: Association between serum concentrations of persistent organic pollutants and insulin resistance among nondiabetic adults: results from the National Health and Nutrition Examination Survey 1999-2002. Diabetes Care 2007; 30: 622-628.

15. Ruderman NB, Schneider SH, Berchtold P: The "metabolically-obese," normal-weight individual. Am J Clin Nutr 1981; 34: 1617-1621.

16. Nakamura T, Tokunaga K, Shimomura I, et al: Contribution of visceral fat accumulation to the development of coronary artery disease in non-obese men. Atherosclerosis 1994; 107: 239-246.

17. Lamarche B, Tchernof A, Mauriege $\mathrm{P}$, et al: Fasting insulin 
and apolipoprotein B levels and low-density lipoprotein particle size as risk factors for ischemic heart disease. JAMA 1998; 279: 1955-1961.

18. World Health Organization: Definition, Diagnosis, and Classification of Diabetes Mellitus and Its Complications: Report of a WHO Consultation. Geneva, World Health Organization, 1999.

19. Balkau B, Charles MA: Comment on the provisional report from the WHO consultation. European Group for the Study of Insulin Resistance (EGIR). Diabetes Med 1999; 16: 442443.

20. Expert Panel on the Detection, Evaluation, and Treatment of High Blood Cholesterol in Adults: Executive summary of the Third Report of the National Cholesterol Education Program (NCEP) Expert Panel on Detection, Evaluation, and Treatment of High Blood Cholesterol in Adults (Adult Treatment Panel III). JAMA 2001; 285: 2486-2497.

21. Einhorn D, Reaven GM, Cobin RH, et al: American College of Endocrinology position statement on the insulin resistance syndrome. Endocr Pract 2003; 9: 237-252.

22. Alverti KGMM, Zimmet P, Shaw J: Metabolic syndrome - a new world-wide definition. A consensus statement from the International Diabetes Federation. Diabet Med 2006; 23: 469-480.

23. Grundy SM, Cleeman JI, Daniels SR, et al: Diagnosis and management of the metabolic syndrome: a statement for health care professionals: an American Heart Association/ National Heart, Lung, and Blood Institute Scientific Statement. Circulation 2005; 112: 2735-2752.

24. Kahn R, Buse J, Ferrannini E, Stern M: The metabolic syndrome: time for a critical appraisal: joint statement from the American Diabetes Association and the European Association for the Study of Diabetes. Diabetes Care 2005; 28: 2289-2304.

25. Grundy SM: Does the metabolic syndrome exist? Diabetes Care 2006; 29: 1689-1692.

26. Kahn R: The metabolic syndrome (emperor) wears no clothes. Diabetes Care 2006; 29: 1693-1696.

27. Reaven GM: The metabolic syndrome: is this diagnosis necessary? Am J Clin Nutr 2006; 83: 1237-1247.

28. Grundy SM: Does a diagnosis of metabolic syndrome have value in clinical practice. Am J Clin Nutr 2006; 83: 12481251

29. Ferrannini E: Metabolic syndrome: a solution in search of a problem. J Clin Endocrinol Metab 2007; 92: 396-398.

30. Grundy SM: Metabolic syndrome: a multiplex cardiovascular risk factor. J Clin Endocrinol Metab 2007; 92: 399-404.

31. Kahn R: Metabolic syndrome. Is it a syndrome? Does it matter. Circulation 2007; 115: 1806-1811.

32. Beaser RS, Levy P: Metabolic syndrome. A work in progress, but a useful construct. Circulation 2007; 115: $1812-1818$.

33. Sundstrom J, Vallhagen E, Riserus U, et al: Risk associated with the metabolic syndrome versus the sum of its individual components. Diabetes Care 2006; 29: 1673-1674.

34. Eckel RH, Kahn R, Robertson RM, Rizza RA: Preventing cardiovascular disease and diabetes: a call to action from the American Diabetes Association and the American Heart Association. Circulation 2006; 113: 2943-2946.

35. Malik S, Wong ND, Franklin SS, et al: Impact of the meta- bolic syndrome on mortality from coronary heart disease, cardiovascular disease, and all causes in United States adults. Circulation 2004; 110: 1245-1250.

36. McNeil AM, Rosamond WD, Girman CJ, et al: The metabolic syndrome and 11-year risk of incident cardiovascular disease in the Atherosclerosis Risk in Communities Study. Diabetes Care 2005; 28: 385-390.

37. Ford ES: Risks for all-cause mortality, cardiovascular disease, and diabetes associated with the metabolic syndrome. Diabetes Care 2005; 28: 1769-1778.

38. Wilson PWF, D'Agostino RB, Parise H, Sullivan L, Meigs JB: Metabolic syndrome as a precursor of cardiovascular disease and type 2 diabetes mellitus. Circulation 2005; 112: 3066-3072.

39. The DECODE Study Group, Qiao Q: Comparison of different definitions of the metabolic syndrome in relation to cardiovascular mortality in European men and women. Diabetologia 2006; 49: 2837-2846.

40. Gami AS, Witt BJ, Howard DE, et al: Metabolic syndrome and risk of incident cardiovascular events and death. $J$ Am Coll Cardiol 2007; 49: 403-414.

41. Ninomiya T, Kubo M, Doi Y, et al: Impact of metabolic syndrome on the development of cardiovascular disease in a general Japanese population. The Hisayama Study. Stroke 2007; 38: 2063-2069.

42. Sone $\mathrm{H}$, Tanaka $\mathrm{S}$, Ishibashi $\mathrm{S}$, et al: The new worldwide definition of metabolic syndrome is not a better diagnostic predictor of cardiovascular disease in Japanese diabetic patients than the existing definitions. Diabetes Care 2006; 29: $145-147$.

43. Katzmarzyk PT, Janssen I, Ross R, Church TS, Blair SN: The importance of waist circumference in the definition of metabolic syndrome. Prospective analyses of mortality in men. Diabetes Care 2006; 29: 404-409.

44. Chen H, Pan W: Probable blind spot in the International Diabetes Federation definition of metabolic syndrome. Obesity 2007; 15: 1096-1100.

45. Yoon YS, Lee ES, Park C, Lee S, Oh SW: The new definition of metabolic syndrome by the International Diabetes Federation is less likely to identify metabolically abnormal but non-obese individuals than the definition by the revised National Cholesterol Education Program: the Korea NHANES Study. Int J Obes 2007; 31: 528-534.

46. Tong PC, Kong AP, So W, et al: The usefulness of the International Diabetes Federation and the National Cholesterol Education Program's Adult Treatment Panel III definitions of the metabolic syndrome in predicting coronary heart disease in subjects with type 2 diabetes. Diabetes Care 2007; 30: 1206-1211.

47. Tanomsup S, Aekplakorn W, Sritara P, et al: A comparison of components of two definitions of the metabolic syndrome related to cardiovascular disease and all-cause mortality in a cohort study in Thailand. Diabetes Care 2007; 30: 2138-2140.

48. Lorenzo C, Serrano-Rios M, Maritinez-Larrad MT, et al: Is waist circumference an essential component of the metabolic syndrome? Diabetes Care 2007; 30: 2141-2142.

49. Klein S, Allison DB, Heymsfield SB, et al: Waist circumference and cardiometabolic risk: a consensus statement from Shaping America's Health: Association for Weight 
Management and Obesity Prevention; NAASO, the Obesity Society; the American Society for Nutrition; and the American Diabetes Association. Diabetes Care 2007; 30: 16471652.

50. Oda E: Criteria for diagnosing the metabolic syndrome. Am J Clin Nutr 2006; 84: 1251-1252.

51. Ogden CI, Carroll MD, Cutin LR, McDowell MA, Tabak CJ, Flegal KM: Prevalence of overweight and obesity in the United States, 1999-2004. JAMA 2006; 295: 1549-1555.

52. Ministry of Health, Labour and Welfere, Japan: The National Health and Nutrition Survey in Japan, 2004. Tokyo, Daiichi Shuppan, 2004 (in Japanese).

53. Adabs KF, Schatzkin A, Harris TB, et al: Overweight, obesity, and mortality in a large prospective cohort of 50 to 71 years old. N Engl J Med 2006; 355: 763-778.

54. Chei CL, Iso H, Yamagishi K, Inoue M, Tsugane S, JPHC Study Group: Body mass index and weight change since 20 years of age and risk of coronary heart disease among Japanese: the Japan Public Health Center-Based Study. Int J Obes (Lond) 2008; 32: 144-151.

55. Kissebah AH, Vydelingum N, Murray R, et al: Relation of body fat distribution to metabolic complications of obesity. J Clin Endocrinol Metab 1982; 54: 254-260.

56. Despres J, Nadeau A, Tremblay A, et al: Role of deep abdominal fat in the association between regional adipose tissue distribution and glucose tolerance in obese women. Diabetes 1989; 38: 304-309.

57. Pouliot MC, Despres J, Lemieux S, et al: Waist circumference and abdominal saggital diameter: best simple anthropometric indices of abdominal visceral adipose tissue accumulation and related cardiovascular risk in men and women. Am J Cardiol 1994; 73: 460-468.

58. Wang Y, Rimm EB, Stampfer MJ, Willett WC, Hu FB: Comparison of abdominal adiposity and overall obesity in predicting risk of type 2 diabetes among men. Am J Clin Nutr 2005; 81: 555-563.

59. Matsuzawa YM: Pathophysiology and molecular mechanism of visceral fat syndrome: the Japanese experience. Diabetes Metab Rev 1997; 13: 3-13.

60. Fox CS, Massaro JM, Hoffmann U, et al: Abdominal visceral and subcutaneous adipose tissue compartments. Association with metabolic risk factors in the Framingham Heart Study. Circulation 2007; 116: 39-48.

61. Pou KM, Massaro JM, Hoffmann U, et al: Visceral and subcutaneous adipose tissue volumes are cross-sectionally related to markers of inflammation and oxidative stress. The Framingham Heart Study. Circulation 2007; 116: 12341241.

62. Kelley DE, Goodpaster BH: Skeletal muscle triglyceride. An aspect of regional adiposity and insulin resistance. Diabetes Care 2001; 24: 933-941.

63. Montani UP, Carroll JF, Dwyer TM, Antic V, Yang Z, Dulloo AG: Ectopic fat storage in heart, blood vessels and kidneys in the pathogenesis of cardiovascular disease. Int $J$ Obes Relat Metab Disord 2004; 28: 558-565.

64. Rasouli N, Molavi B, Elbein SC, Kern PA: Ectopic fat accumulation and metabolic syndrome. Diabetes Obes Metab 2007; 9 (1): 1-10.

65. Kotronen A, Yki-Jarvinen H: Fatty liver: a novel component of the metabolic syndrome. Arterioscler Thromb Vasc
Biol 2008; 28: 27-38.

66. Hotamisligil GS, Shargill NS, Spiegelman BM: Adipose expression of tumor necrosis factor- $\alpha$ : direct role in obesitylinked insulin resistance. Science 1993; 259: 87-91.

67. Zhang Y, Proenca R, Maffei M, Barone M, Leopold L, Friedman JM: Positional cloning of the mouse obese gene and its human homologue. Nature 1994; 372: 425-432.

68. Maeda K, Okubo K, Shimomura I, Funahashi T, Matsuzawa Y, Matsubara K: cDNA cloning and expression of a novel adipose specific collagen-like factor, apM1 (adipose most abundant gene transcript 1). Biochem Biophy Res Commun 1996; 221: 286-298.

69. Steppan CM, Bailey ST, Bhat S, et al: The hormone resistin links obesity to diabetes. Nature 2001; 409: 307-312.

70. Fukuhara A, Matsuda M, Nishizawa M, et al: Visfatin: a protein secreted by visceral fat that mimicks the effects of insulin. Science 2005; 307: 426-430.

71. Takahashi K, Mizuarai S, Araki H, et al: Adiposity elevates plasma MCP-1 levels leading to the increased CD11b-positive monocytes in mice. J Biol Chem 2003; 278: 4665446660.

72. Yang Q, Graham TE, Mody N, et al: Serum retinol binding protein 4 contributes to insulin resistance in obesity and type 2 diabetes. Nature 2005; 436: 356-362.

73. Xu A, Wang Y, Xu JY, et al: Adipocyte fatty acid binding protein a plasma biomarker closely associated with obesity and metabolic syndrome. Clin Chem 2006; 52: 405-413.

74. Dandona $\mathrm{P}$, Aljada A, Mohanty $\mathrm{P}$, et al: Insulin inhibits intranuclear nuclear factor kappaB and stimulates IkappaB in mononuclear cells in obese subjects: evidence for an antiinflammatory effect? J Clin Endocrinol Metab 2001; 86: 3257-3265.

75. Hotamisligil GS: Role of endoplasmic reticulum stress and c-Jun $\mathrm{NH}_{2}$-terminal kinase pathways in inflammation and origin of obesity and diabetes. Diabetes 2006; 54: S73-S78.

76. Semenkovich CF: Insulin resistance and atherosclerosis. $J$ Clin Invest 2006; 116: 1813-1822.

77. Kim JY, Wall E, Laplante M, et al: Obesity-associated improvements in metabolic profile through expansion of adipose tissue. J Clin Invest 2007; 117: 2621-2637.

78. Bains RK, Wells SE, Flavell DM, et al: Visceral obesity without insulin resistance in late-onset obesity rats. Endocrinology 2004; 145: 2666-2679.

79. Cinti S, Mitchell G, Barbatelli G, et al: Adipocyte death defines macrophage localization and function in adipose tissue of obese mice and humans. J Lipid Res 2005; 46: 23472355.

80. Kanda H, Tateya S, Tamori Y, et al: MCP-1 contributes to macrophage infiltration into adipose tissue, insulin resistance, and hepatic steatosis in obesity. J Clin Invest 2006; 116: $1494-1505$.

81. Kamei N, Tobe K, Suzuki R, et al: Overexpression of monocyte chemoattractant protein-1 in adipose tissue causes macrophage recruitment and insulin resistance. $J$ Biol Chem 2006; 281: 26602-26614.

82. Wellen KE, Fucho R, Gregor MF, et al: Coordinated regulation of nutrient and inflammatory response by STAMP2 is essential for metabolic homeostasis. Cell 2007; 129: 537548.

83. Strissel KJ, Stancheva Z, Miyoshi H, et al: Adipocyte death, 
adipose tissue remodeling, and obesity complications. Diabetes 2007; 56: 2910-2918.

84. Kolak M, Westerbacka J, Velagapudi VR, et al: Adipose tissue inflammation and increased ceramide content characterize subjects with high liver fat content independent of obesity. Diabetes 2007; 56: 1960-1968.

85. Han TS, Satter N, Williams K, Gonzalez-Villalpando C, Lean MEJ, Haffner SM: Prospective study of C-reactive protein in relation to the development of diabetes and metabolic syndrome in the Mexico City Diabetes Study. Diabetes Care 2002; 25: 2016-2021.

86. Sattar N, Gaw A, Scherbakova O, et al: Metabolic syndrome with and without $\mathrm{C}$-reactive protein as a predictor of coronary heart disease and diabetes in the West of Scotland Coronary Prevention Study. Circulation 2003; 108: 414419.

87. Nakanishi S, Yamane K, Kamei N, et al: Elevated C-reactive protein is a risk factor for the development of type 2 diabetes in Japanese Americans. Diabetes Care 2003; 26: 2754-2757.

88. Rutter MK, Meigs JB, Sullivan LM, D'Agostino RB, Wilson PWF: C-reactive protein, the metabolic syndrome, and prediction of cardiovascular events in the Framingham Offspring Study. Circulation 2004; 110: 380-385.

89. Ridker PM, Cook N: Clinical usefulness of very high and very low levels of C-reactive protein across the full range of Framingham Risk Scores. Circulation 2004; 109: 19551959.

90. Malik S, Wong ND, Franklin S, Pio J, Fairchild C, Chen R: Cardiovascular disease in U.S. patients with metabolic syndrome, diabetes, and elevated C-reactive protein. Diabetes Care 2005; 28: 690-693.

91. Doi Y, Kiyohara Y, Kubo M, et al: Elevated C-reactive protein is a predictor of the development of diabetes in a general Japanese population. Diabetes Care 2005; 28: $2497-$ 2500.

92. Dehghan A, van Hoek M, Sijbrand EJG, Stijnen T, Hofman A, Witteman JCM: Risk of type 2 diabetes attributable to Creactive protein and other risk factors. Diabetes Care 2007; 30: $2695-2699$.

93. Sabatine MS, Morrow DA, Jablonski KA, et al: Prognostic significance of the Centers for Disease Control/American Heart Association high-sensitivity C-reactive protein cut points for cardiovascular and other outcomes in patients with stable coronary artery disease. Circulation 2007; 115: 1528-1536.

94. Shamsuzzaman ASM, Winnicki M, Wolk R, et al: Independent association between plasma leptin and C-reactive protein in healthy humans. Circulation 2004; 109: 2181-2185.

95. Matsushita K, Yatsuya H, Tamakoshi K, et al: Inverse association between adiponectin and C-reactive protein in substantially healthy Japanese men. Atherosclerosis 2006; 188: 184-189.

96. Nakamura $\mathrm{H}$, Ito $\mathrm{H}$, Egami $\mathrm{Y}$, et al: Waist circumference is the main determinant of elevated C-reactive protein in metabolic syndrome. Diabetes Res Clin Pract 2008; 79: 330-336.

97. Komatsu M, Ohfusa H, Aizawa T, Hashizume K: Adiponectin inversely correlates with high-sensitivity C-reactive protein and triglycerides, but not with insulin sensitivity in apparently healthy Japanese men. Endocrine $J$ 2007; 54: 553-558.

98. Yoneda M, Mawatari H, Fujita K, et al: High-sensitivity Creactive protein is an independent clinical feature of nonalcoholic steatohepatitis (NASH) and also of the severity of fibrosis in NASH. J Gastroenterol 2007; 42: 573-582.

99. Oda E, Oohara K, Abe A, et al: The optimal cut-off point of C-reactive protein as an optional component of metabolic syndrome in Japan. Circ J 2006; 70: 384-388.

100. Saijo Y, Yoshioka E, Fukui T, Kawaharada M, Kishii R: Metabolic syndrome, C-reactive protein and increased arterial stiffness in Japanese subjects. Hypertens Res 2006; 29: 589-596.

101. Matsushita K, Yatsuya H, Tamakoshi K, et al: High-sensitivity C-reactive protein is quite low in Japanese men at high coronary risk. Circ J 2007; 71: 820-825.

102. Itoh T, Mizuno Y, Harada E, Yoshimura M, Ogawa H, Yasue H: Coronary spasm is associated with chronic lowgrade inflammation. Circ J 2007; 71: 1074-1078.

103. Christakis NA, Fowler JH: The spread of obesity in a large social network over 32 years. N Engl J Med 2007; 357: 370-379. 